DOI: http://dx.doi.org/10.22484/2177-5788.2017v43n1p33-53

\title{
Projetos políticos emancipatórios e cultura da memória no capitalismo contemporâneo
}

\author{
Felipe Correa de Mello
}

Resumo: Propomos fazer alguns apontamentos acerca da relação entre imagem, memória e política na sociedade contemporânea. Como ilustração de nossa exposição, analisamos o trabalho realizado pelo Museo de la Memoria y los Derechos Humanos de Santiago, Chile. Em nosso percurso expositivo fazemos apontamentos sobre a efemeridade do tempo e a centralidade da imagem em nossa sociedade, em seguida, fazemos algumas considerações sobre o fenômeno de mercantilização da memória, bem como acerca dos potenciais políticos/educativos da memória coletiva sobre acontecimentos históricos de sistemática violação dos direitos humanos (como o Holocausto e as ditaduras latino-americanas). $\mathrm{Na}$ última parte, fazemos uma análise de três instalações do Museo.

Palavras-chave: Memória. Direitos humanos. Imagens.

\section{Emancipatory political projects and culture of memory in contemporary capitalism}

Abstract: We propose to make some notes about the relation between image, memory and politics in contemporary society. As an illustration of our exhibition, we analyze the work carried out by the Museum of Memory and Human Rights of Santiago, Chile. In our exposition we make notes on the ephemerality of time and the centrality of the image in our society, then we make some considerations about the consumption of memories in contemporary capitalism as well as about the political / educational potentials of the collective memory about historical events of systematics violation of human rights (such as the Holocaust and Latin American dictatorships). In the last part, we make an analysis of three installations of the Museum.

Keywords: Memory. Human rights. Images. 


\section{Introdução}

Nesse artigo propomos fazer alguns apontamentos acerca da relação entre imagem, memória e política na sociedade contemporânea.

Como ilustração de nossa exposição, propomos analisar o trabalho realizado pelo Museo de la Memoria y los Derechos Humanos do Chile - instituição voltada para a preservação e comunicação das memórias e narrativas históricas sobre a ditadura de Pinochet (1973-1990).

Nossa opção pelo Museo se dá porque esse, ao nosso ver, realiza um importante trabalho no campo da memória e da educação em direitos humanos, sobretudo no que diz respeito ao uso de imagens e instalações artísticas, constituindo-se como uma valiosa unidade de análise para a compreensão das "brechas" políticas numa sociedade, segundo Harvey (2001), marcada pela efemeridade temporal e pelo excesso de informações e imagens, ou "hipertelia", nos termos de Baudrillard (1991).

Em nosso percurso expositivo, apresentamos, num primeiro momento, apontamentos sobre a efemeridade do tempo e a centralidade da imagem em nossa sociedade. Em seguida, tendo como eixo condutor as reflexões do professor alemão Andrea Huyssen (2014), fazemos algumas considerações sobre o fenômeno de mercantilização da memória, bem como acerca dos potenciais políticos/educativos da memória coletiva sobre acontecimentos históricos de sistemática violação dos direitos humanos (como o Holocausto e as ditaduras latinoamericanas). Na última parte, fazemos uma análise de três instalações do Museo, com o propósito de ilustrar as considerações feitas nas duas primeiras partes do artigo.

\section{Efemeridade, velocidade e hipertelia}

No livro A condição pós-moderna, David Harvey (2001) nos mostra que a transição do fordismo para a acumulação flexível é inseparável de mudanças na experiência social do espaço e do tempo. Designada pelo autor como "compressão do tempo-espaço" essa nova experiência tem tido, a partir da década de 1970 até os dias de hoje, "um impacto desorientado e disruptivo sobre as práticas político-econômicas, sobre o equilíbrio do poder de classe, bem como sobre a vida social e cultural” (HARVEY, 2001, p. 257). 
Em linhas gerais, a aceleração do tempo de giro da produção econômica, característica do novo modelo, implica dois processos sincrônicos e contraditórios: por um lado, a dispersão e a fragmentação espacial e temporal; por outro, a compressão do espaço e do tempo. Nesse cenário, experimenta-se a ruptura de fronteiras e distâncias espaciais, bem como o domínio do instante sobre o futuro e o passado. Em outros termos: o capitalismo contemporâneo, segundo Chiaui (2008), marcado pela vivência de um espaço indiferenciado (composto por uma multiplicidade de imagens sobrepostas) e um tempo efêmero e volátil, desprovido de profundidade.

Paul Virilio (2008) fala de uma colonização territorial por parte do tempo. Para o autor, na sociedade contemporânea os espaços físicos foram tomados pelo tempo, tornando-se instâncias sociais secundárias. Nossas vidas, segundo o mesmo autor, são regidas por um marcador temporal de velocidade que produz uma experiência vazia de profundidade — quer dizer, destituída da profundidade caraterística das dimensões físicas da geometria.

Esse acontecimento está relacionado, dentre outros fatores, ao avanço das novas formas tecnológicas de produção e circulação de informação. Essas, são responsáveis pela produção abundante e extremamente veloz de bens simbólicos, segundo Virilio (2008), levando a um excesso de informações e de imagens que acabam por deslocar nossa percepção das figuras dos objetos em direção às suas formas. Assim, na sociedade contemporânea a aparência das imagens e dos objetos constituem-se como um dos reguladores centrais de nossa compreensão do mundo.

Tangencialmente ao pensamento de Virilio (2008), Baitello (2005, p. 43) usa a expressão "perda do presente" para caracterizar a incapacidade que o sujeito contemporâneo tem em estar em seu tempo, uma vez que o "tempo presente tem se desdobrado em tantas dimensões e possibilidades que se esgarçou e esvaneceu, oferecendo um sem número de vias de escape e fuga" (BAITELLO, 2005, p. 43). O fenômeno de inflação das imagens é um dos aspectos desse processo de aceleração do tempo.

Baitello (2005) se refere à sociedade contemporânea como a "era da iconofagia". Segundo Baitello (2005, p. 14), o desenvolvimento de tecnologias de reprodução de bens simbólicos "abriu as portas para uma escalada das imagens visuais que começaram a competir pelo espaço e pela atenção (vale dizer, pelo tempo de vida) das pessoas". Devoramos e somos 
devorados pelas imagens: "consumimos imagens em todas as suas formas: marcas, modas, grifes, tendências, atributos, adjetivos, figuras, ídolos, logomarcas" (BAITELLO, 2005, p. 54). E dado o excesso de imagens, consumimos delas tão somente suas epidermes, "suas superfícies superficializadas" (BAITELLO, 2005, p. 54).

Como uma das consequências desse fenômeno, segundo Baitello (2005), o ato do pensamento é profundamente impactado pelas imagens e pelos aparelhos de produção simbólica num processo que resulta numa espécie de "fadiga do olhar". Numa certa incapacidade em compreender, reter e analisar as mensagens.

De forma mais radical e em um tom polêmico e apocalíptico Baudrillard (1991) fala de "hipertelia" e anuncia a desrealização de nosso mundo: o excesso de imagens, a obesidade e obscenidade de informação caracterizam uma sociedade que habita um mundo de simulacros. De aparências, de vazio. Nesse contexto, o projeto moderno iluminista não é possível. Não há espaço para a política, para a o conhecimento e para a arte.

Nesse sentido, a mudança das experiências espaciais e temporais implicam, para Virilio (2008), uma crise do espaço público e da cidadania que nos impede de pensarmos uma prática política emancipatória e democrática:

\begin{abstract}
Ubiquidade, instantaneidade, o povoamento do tempo suplanta o povoamento do espaço [...] índice cataclísmico de uma desintegração próxima da cidade histórica, da urbanização tradicional e, igualmente, da forma-Estado [...] Estado de direito civil cuja degradação é hoje tão manifesta quanto a forma metropolitana e da qual a própria noção de "Direitos do Homem" (sic) indica claramente o nível de crise; crise de identidade nacional, crise consecutiva da cidadania territorial, da localização, desmesura que afeta simultaneamente os locais, os homens, a justiça e o direito politicamente comparável à crise da noção de dimensão (VIRILIO, 2008, p. 95- 97, grifo nosso).
\end{abstract}

Segundo o diagnóstico de Virilio (2008) e de Baudrillard (1991) vivemos numa era de desintegração do tecido social, caracterizada pela fragmentação dos indivíduos, pela ruptura das fronteiras espaciais e pela descontinuidade ontológica. Nessa sociedade, o sujeito experimenta uma vivência de profunda instabilidade e de desenraizamento. A única temporalidade experimentada é a do presente instantâneo e efêmero. O passado se esvanece diante da aceleração frenética inerente a todas as esferas da vida social; o futuro torna-se incerto, nebuloso. 


\section{A mercantilização da memória}

Em tese o excesso de imagens e a efemeridade temporal produz um fenômeno de amnésia social. Num espaço no qual não há comunicação - compreendida como criação de vínculos ${ }^{1}$ - e no qual o passado é diluído na instantaneidade do presente, poucas imagens e mensagens chegam a remeter à memória e à história. Tudo se esquece. O que se retém é a memória do instante, conforme Virilio (2006), que pela própria dinâmica social em breve é esquecida.

Por outro lado, o processo de memorialização, como todos os fenômenos sociais contemporâneos, é revestido de uma complexidade nunca antes experimentada. No cenário atual, as conexões entre sujeitos e mensagens em circulação existem numa escala abundante. Nunca antes existiram tantos dispositivos tecnológicos de registro e comunicação da memória, tampouco nunca houve a quantidade de agentes sociais que as produzem. Fotos, testemunhos, reportagens, vídeos etc. relatam o presente e transbordam o ciberespaço numa imensidão de experiências pessoais e coletivas.

No entanto, a questão é mais profunda. Conforme nos mostra Huyssen (2014) vivemos numa sociedade amplamente marcada por uma "cultura da memória". Desde meados da década de 1970, há na sociedade Ocidental um movimento de resgate do passado que perpassa grande parte das esferas midiáticas e mercantis. Dentre os exemplos que sustentam sua afirmação, o autor elenca: "a restauração historicizante dos velhos centros urbanos, aldeias, museus e paisagens inteiras por parte de várias empresas de patrimônio nacional; a onda da nova arquitetura de museus que não mostra sinais a retroceder" (HUYSSEN, 2014, p. 12); o boom da moda retrô que atravessa diversos campos, como os da música, da mobília e do vestuário; o abundante crescimento de autobiografias, de literatura confessional e de romances históricos pós-modernos, "com sua negociação pouco confortável entre fato e ficção"; a mercantilização e espetacularização do Holocausto em diversos formatos, como filmes, museus, dramas cinematográficos, livros e quadrinho; “o alastrar das práticas de memória nas artes visuais muitas vezes centradas no meio da fotografia"; bem como o aumento dos documentários

\footnotetext{
1 Sobre comunicação e criação de vínculos ver Baitello (2005).
} 
históricos na televisão, incluindo (nos EUA) um canal inteiramente dedicado à história" (HUYSSEN, 2014, p. 12).

O autor é enfático em sua tese e afirma que "estamos construindo museus como se não houvesse amanhã" (HUYSSEN, 2014, p. 18), chegando ao ponto de a memória tornar-se "uma obsessão cultural de proporções monumentais em todo o globo". Em certo trecho de sua argumentação, o autor afirma que a "máquina da memória" foi cooptada pela indústria cultural (HUYSSEN, 2014, p. 20).

A interpretação de Huyssen (2014) é reforçada por Beatriz Sarlo que investiga em Tempo passado: cultura da memória e guinada subjetiva (2005) os testemunhos de ex-presos e familiares de vítimas da ditadura militar argentina (1976-1983):

As últimas décadas deram a impressão de que o império do passado se enfraquecia diante do "instante" os lugares-comuns sobre a pós-modernidade, com suas operações de "apagamento", repicam o luto ou celebram a dissolução do passado); no entanto, também foram as décadas da museificação, da heritage, do passado-espetáculo, das aldeias Potemkim e dos theme-park históricos; daquilo que Ralph Samuel chamou de "mania preservacionista"; do surpreendente renascer do romance histórico, dos bestsellers e filmes que visitam desde Troia até o século XIX, das histórias da vida privada, por vezes indiferenciáveis do costumbrismo, da reciclagem de estilos, tudo isso que Nietzsche chamou, irritado, de história dos antiquários (SARLO, 2005, p. 11).

Harvey (2001) também contempla tal fenômeno fornecendo pistas de como o marketing se apropria do passado como estratégia de construção de imagem de marcas e empresas. Num mercado definido pela competição extremamente acirrada, diz o autor, a construção da identidade de marca é um fator crítico de sucesso. Em meio a tantas imagens as quais os consumidores são expostos, é fundamental que a marca de dada empresa seja imediatamente reconhecida. A vantagem competitiva é conquistada, entre outros fatores, pelo uso eficaz que a empresa faz das imagens, associando, assim, sua identidade a valores tais como "respeitabilidade", "quantidade", "prestígio", "confiabilidade” e "inovação" (HARVEY, 2001, p. 260).

Nesse contexto aludido pelo geógrafo inglês, as imagens não servem somente para produzir o sentido de novidade - e dessa forma, contribuírem para a aceleração do tempo de giro de consumo - , mas também cumprem a função de estabelecer uma certa permanência que garanta a manutenção da identidade da marca. Conforme mostra a teoria de branding, segundo 
Lindstrom (2005), a marca é construída através de enormes gastos de comunicação e marketing, num processo lento e progressivo de conquista dos corações e mentes dos consumidores. Sua consequência fundamental, garantir relações duradouras com esses consumidores (fidelização).

Dessa forma, num percurso aparentemente paradoxal, o efêmero e o estável, o novo e o tradicional se articulam:

Tanto as corporações como os governos e os líderes intelectuais e políticos valorizam uma imagem estável (embora dinâmica) como parte de sua aura de autoridade e poder [...] a produção e venda dessas imagens de permanência e de poder requerem uma sofisticação considerável, porque é preciso conservar a continuidade e a estabilidade da imagem enquanto se acentuam a adaptabilidade, a flexibilidade e o dinamismo do objeto, material ou humano, da imagem (HARVEY, 2001, p. 260).

Como nos informa a Escola dos Annales, a história não é constituída por um movimento em linha reta regulado por relações de causa e efeito. Sua dinâmica é marcada pela sobreposição de diversas temporalidades; pela convivência de estruturas de tempos de longa e de curta duração (Braudel). Nesse sentido, Harvey (2001) nos mostra que a modernidade fordista e a pós-modernidade flexível não constituem formações sociais e históricas homogêneas. A despeito de serem "dois regimes de acumulação bem diferentes" — e, por isso, encerrarem modos distintos de regulação - , podemos observar, em nossa sociedade, a convivência de elementos característicos de ambos. Assim, o autor nos convida a pensar a "pós-modernidade" articulada à modernidade.

Entretanto, ainda observa Harvey (2001), num cenário fortemente marcado pela efemeridade é natural que as pessoas voltem seu interesse para instituições básicas, como a família e a comunidade, e que busquem raízes históricas que possam vir a garantir hábitos e valores duradouros.

Essa afirmação é análoga à hipótese de Huyssen (2014, p. 17) de que em nossa sociedade a guinada em direção à memória é, de forma subliminar, "estimulada pelo desejo de nos ancorarmos num mundo caracterizado pela cada vez maior instabilidade do tempo e pela fragmentação do espaço vivido".

Huyssen (2014, p. 15-18) relaciona a "obsessão pela memória" tanto às incertezas sociais sobre o futuro quanto ao medo do esquecimento - processos que tendem a reforçar essa sensação de desenraizamento. Segundo nos mostra Huyssen (2014), a partir da década de 
1970 o tema da memória foi alavancado, ganhando ampla visibilidade tanto nos debates públicos quanto na indústria cultural. Esse fenômeno está relacionado, segundo ele, a uma multiplicidade de fatores de ordem social e política, incluindo o fim do apartheid na África do Sul, o colapso da União Soviética, o fim das ditaduras na América Latina, bem "como o crescente foco cultural nas histórias de minorias e políticas de identidade" (HUYSSEN, 2014, p. 331). Num sentido mais amplo, Huyssen (2014) compreende que o interesse global pelas memórias coletivas é resultado do "naufrágio" do imaginário das utopias, algo característico dos projetos modernistas do século XX. Assim, conforme Huyssen (2014), o crescimento das iniciativas memorialísticas está relacionado à busca de novas tradições que são acompanhadas pelas múltiplas afirmações acerca do fim da história, o fim do sujeito, o fim da obra de arte, o fim das metanarrativas.

Nessa chave interpretativa, o mesmo autor indaga se estamos vivendo ao mesmo tempo um boom de memória e um boom de esquecimento. Sem responder à questão, o autor, no entanto, nos dá pistas que indicam a relação desse provável fenômeno com a forte presença do consumo e da comunicação em nossa sociedade:

Freud lembrou que memória e esquecimento estão indissoluvelmente ligados [...]. No entanto, o que Freud descreveu em termos universais como processo psíquico de lembrar, reprimir e esquecer nos indivíduos, está claramente em evidência nas sociedades de consumo contemporâneas enquanto fenômeno público de proporções sem precedentes que pede para ser lido historicamente [...] (HUYSSEN, 2014, p. 16).

Pensando a relação entre memória e esquecimento a partir da interface comunicação e consumo, Huyssen (2014) se posiciona contra alguns críticos do capitalismo tardio, como os supracitados Jean Baudrillard e Paul Virilio, que enxergam na mercantilização da memória nada mais do que um processo de amnésia e/ou de alienação. Para o autor esses pensadores estão apegados à crítica adorniana à indústria cultural, e por isso são incapazes de compreender o caráter ambivalente dos produtos mercantis de memória.

Conforme argumenta Huyssen (2014, p. 18), mesmo que dado acontecimento histórico "tenha sido infindavelmente mercantilizado isso não significa que toda e qualquer uma das mercantilizações inevitavelmente o banalizem enquanto evento histórico”. A contraposição entre a "memória séria" (como o projeto Shoah, como uma tese de doutorado sobre o Holocausto etc.) e a "memória trivial" (um produto da indústria cultural como o filme a Lista 
de Schindler) só reproduz a velha dicotomia entre alta cultura e baixa cultura. Na sociedade de consumo, os bens simbólicos se cruzam, entram em embates, dialogam entre si numa complexa trama cultural que nos impede de fazermos julgamentos simplistas e redutores.

Sua proposta é pensar a articulação entre ambos os tipos de memórias. Afinal, essas ocupam o mesmo espaço público, estando as questões da cultura da memória localizadas "no limite entre memória traumática e os media comerciais" (HUYSSEN, 2014, p. 18).

Essa postura de Huyssen se articula às reflexões de Baccega $(2010 ; 2012)$ que defende que o campo da Comunicação/Educação e Consumo, constituído como lugar privilegiado na construção dos sentidos sociais, deve contribuir para a reflexão acerca das concepções e das práticas de consumo que perpassam o conjunto da vida social, e nesse caminho deve mostrar que o consumo não se reduz ao consumismo, sendo "[...] indispensável à existência de qualquer sociedade" (BACCEGA, 2010, p. 52).

Da mesma forma que o campo da Comunicação/Educação e Consumo tem como uma de suas tarefas principais mostrar que o consumo é uma atividade complexa que não pode ser reduzida à sua faceta negativa (o consumismo), as reflexões de Huyssen (2014) nos convidam a pensar os potenciais políticos e educativos (no sentido da formação de cidadãos) das memórias coletivas mercantilizadas sem que tenhamos que a priori descartá-las por se tratarem de produtos inseridos na lógica capitalista.

Entretanto, conforme argumenta Huyssen (2014), se por um lado romper com a oposição entre os "bens mercantis de memória" e os produtos da "memória séria" seja analiticamente fértil para darmos conta da complexidade da sociedade contemporânea, atravessada pelas práticas de consumo; por outro, não devemos nos furtar a um exercício que vise a separar as memórias coletivas voltadas para a formação de uma cultura de valorização dos direitos humanos de memórias fetichizadas que levam tão somente à uma contemplação passiva do passado.

Nesse sentido, o autor propõe uma reflexão acerca dos usos sociais e políticos que fazemos da memória coletiva, destacando-se as memórias relacionadas a acontecimentos traumáticos e de sistemática violação dos direitos humanos e que possam contribuir para a construção de uma sociedade justa e igualitária. 
Embora a "cultura da memória" seja um fenômeno de proporções globais, ela assume "diferentes intensidades em diferentes partes do mundo, e as lutas por um futuro melhor, evidentemente, não desapareceram".

Para Huyssen (2014), na América Latina, na Austrália e em alguns países da África, do Leste europeu e da Ásia, a "cultura da memória” possui um acento marcadamente político, voltado para projetos de direitos humanos e de transformação do status quo. Nesse sentido, diferencia-se da maior parte das iniciativas de memorialização realizadas na Europa e nos EUA, caracterizadas por uma recuperação fetichista e politicamente vazia — discursos da memória que buscam na celebração do passado a legitimação do presente:

\begin{abstract}
O que aparece aqui [sociedades Ocidentais do Atlântico Norte] como um marketing cada vez mais bem-sucedidos por parte da indústria cultural [...] adquire uma inflexão mais explicitamente política noutras partes do mundo. Especialmente a partir de 1989, as temáticas da memória e do esquecimento emergiram como preocupações dominantes em países pós-comunistas na Europa do Leste e na antiga União Soviética; permanecem enquanto assuntos políticos chave no Médio Oriente; dominaram o discurso público na África do Sul com a sua Comissão para a Verdade e Reconciliação; e são onipresentes no Ruanda e na Nigéria; estimulam o debate racial que estalou na Austrália em torno da "geração roubada"; sobrecarregam a relação entre Japão e a China e a Coreia; e determinam em diferentes níveis, o debate cultural e político acerca dos "desaparecidos" e dos seus filhos nas sociedade pós-ditadura na América Latina [...] (HUYSSEN, 2014, p.13-4).
\end{abstract}

Em seu estudo, Huyssen (2014, p. 32) propõe separar as memórias coletivas "produtivas" das memórias coletivas "não produtivas". As memórias "produtivas" são aquelas que estão voltadas para a recuperação do passado com vistas a projetos políticos de transformação da sociedade e que encontram sua concretização em iniciativas como os museus e memoriais voltados para as memórias das ditaduras latino-americanas. As memórias "não produtivas" estão concentradas em iniciativas museológicas que buscam a reconstituição do passado "tal como ele ocorreu" como os "museus da história viva" que realizam encenações sobre batalhas da guerra civil norte-americana, nos EUA. Grosso modo, podemos aproximar a noção de "memória produtiva" ao que Meneses (1994) denomina de "Laboratórios da História": espaços museológicos voltados para a reflexão dos sentidos, tensões e contradições implicados na constante (re) construção do discurso histórico e que se opõem aos "Teatros da Memória": espaços voltados para tão somente a contemplação do passado "em si", sem qualquer articulação com o presente. 


\section{Memória, imagem e política: o Museo de la Memoria y los Derechos Humanos de Santiago, Chile}

Dentre as iniciativas memorialísticas voltadas para a comunicação das narrativas de violação sistemática dos direitos humanos na América do Sul, podemos destacar o Museo de la Memoria Abierta, de Buenos Aires, situado na sede da antiga Escola de Mecânica de La Armada (Ex-ESMA), um dos principais centros de tortura e detenção da ditadura militar argentina (1976-193); o Memorial de los Detenidos y Desaparecidos, em Montevidéu, Uruguai; o Memorial da Resistência do Estado de São Paulo, localizado no antigo prédio que pertenceu ao Departamento Estadual de Ordem Política e Social de São Paulo - DEOPS/SP, durante o período de 1940 a 1983 e o Museo de La Memoria y los Derechos Humanos de Santiago de Chile, voltado para a preservação e comunicação das memórias sobre a ditadura de Augusto Pinochet (1973-1990).

Considerado por Seligmann-Silva (2014) como a instituição museológica mais bemsucedida da América Latina em realizar a interface entre memória, política e educação para a democracia, o Museo de la Memoria do Chile foi criado em 2010, a partir de um projeto que teve sua origem em junho de 2007, por iniciativa do Ministério de obras públicas do governo de Michellle Bachelet - Partido Socialista do Chile (MUSEO DE LA MEMORIA, 2016). Seu edifício foi projetado a partir de concurso nacional e internacional vencido por uma equipe de arquitetos de São Paulo. Em seu exterior está localizada a Plaza de la Memoria, onde são realizados concertos e diversas manifestações culturais.

O espaço do museu abriga diversas exposições temporárias, envolvendo diversas exposições de arte, contando com artistas internacionais e chilenos, bem como uma exposição fixa, contando com murais, fotos, vídeos informativos, documentos, instalações artísticas e textos sobre o contexto contemplado pelo museu. 
Segundo nos informou o diretor executivo da instituição, Marcelo Brodsky em palestra realizada no Instituto de Estudos Avançado da USP em novembro de $2014^{2}$ instituição foi concebida como um espaço de arte e educação e sua a proposta é estar inserida no cotidiano e na política do Chile. Nesse contexto, a imagem constitui um elemento central na (re) construção e comunicação das memórias da ditadura chilena. As imagens evocam a memória desses acontecimentos e são construídas com o intuito de gerar tanto um impacto emocional quanto educacional.

\section{Alguns apontamentos sobre imagem, memória e política a partir de três instalações do Museo de la Memória}

Quando falamos de história e de memória temos que ter em conta a importância das imagens como documentos indispensáveis. Muito do conhecimento que possuímos de acontecimentos históricos de sistemática violação dos direitos humanos são fornecidos por imagens; sobretudo fotografias e vídeos.

Mais: o poder simbólico da foto/vídeo é enorme pois opera como atestado de veracidade do acontecimento. Amparadas pelos testemunhos e por outras fontes documentais, as fotos nos mostram que o Holocausto, o Apartheid, a tortura durante as ditaduras latino-americanas etc. de fato ocorreram. Em contrapartida, sua ausência coloca um desafio para aqueles que buscam rememorar certos episódios, como é o caso do genocídio do povo armênio no início do século $\mathrm{XX}$.

A imagem é um texto/linguagem que comunica e educa. Nesse sentido, ela não se encontra somente no registro da alienação política, como Baudrillard (1991) concebe ao criticar a condição de "hipertelia" de nossa sociedade.

Conforme nos ensina Machado (2001), o filósofo francês retoma o queixume de Platão em relação ao caráter inapreensível da realidade por meio de nossos sentidos: o que Baudrillard lamenta como perda do real, Machado concebe ser própria dinâmica de nossa sociedade. Ou seja, a centralidade da imagem em nossa sociedade é um fato inexorável. Vivemos uma

\footnotetext{
${ }^{2}$ Memória e arte em direitos humanos, mesa V. Cartografia dos Direitos Humanos, evento organizado pelo Instituto de Estudos Avançados da USP, 7 nov. 2014.
} 
sociedade do visual. As imagens transbordam e estruturam nosso cotidiano. Como lidar com elas é a questão política que se coloca. E ao contrário do pessimismo de Baudrillard, Machado enxerga (propõe) caminhos.

Além do mais, em certa medida, o problema não é em si o excesso de imagens, mas sim o tempo que devemos ter para estabelecer análises e conexões. Para transformar informações fragmentadas em vínculos. Em comunicação.

Em suma: num mundo de imagens e de efemeridade não há só alienação. Há potencialidades para o pensamento e para a política. Não é necessário só o verbal para expor conceitos e transmitir experiências traumáticas. Além do mais, nessa sociedade é preciso explorar o potencial das imagens para educar e conscientizar (e por que não, entreter?).

Assim, obras como a Geometria de la consciência, de Alfredo Jaar (Fig. 1), integrante da exposição permanente do Museo de la Memoria, nos convidam a pensar nas potencialidades emancipatórias presente na explosão das imagens em nossa sociedade, como, por exemplo, segundo Canevacci (2008), o de construir e comunicar novas experiências identitárias.

Figura 1 - Parte da instalação Geometria de la conciencia

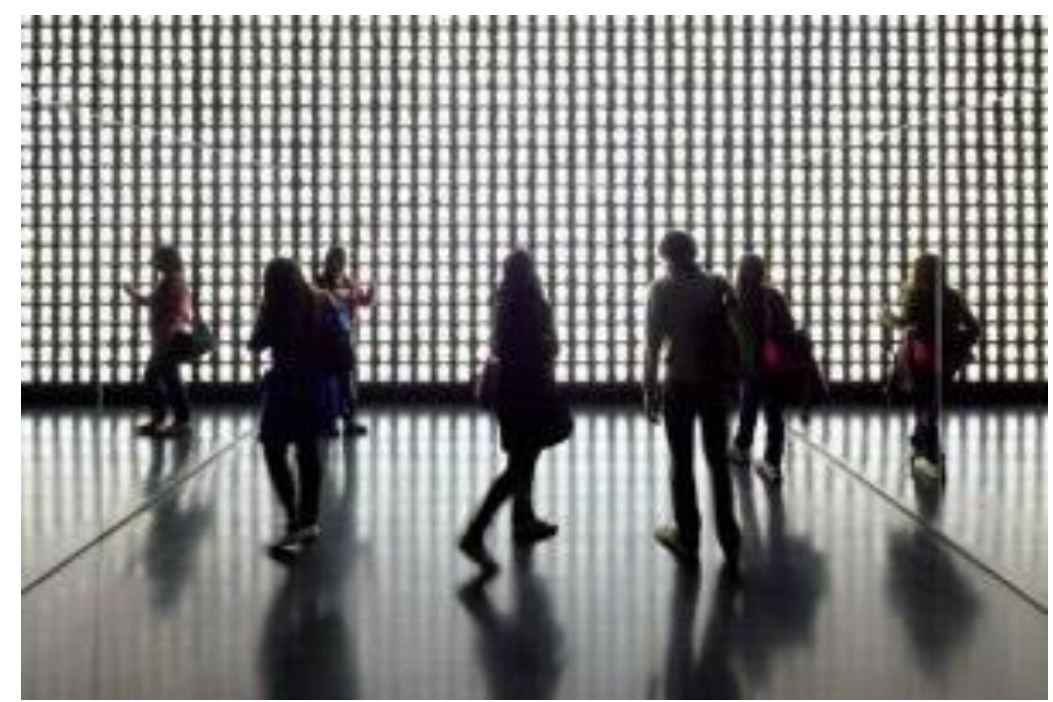

Fonte: Arquivo do Museo de la Memoria y de los Derechos Humanos. Disponível em: <http://estudiopalma.cl/upfiles/galerias/4c508eb96ecde_Geometria-de-la-conciencia-305.jpg>. Acesso em: 10 abr. 2017. 
Nessa instalação não há a presença de dados históricos, datas ou textos. É uma obra destinada a exploração aberta e complexa de sentimentos e pensamentos. No mural, pouco iluminado estão presentes 500 silhuetas de rostos, que intermitentemente aparecem e desaparecem. Não há em nenhuma delas a identificação de cada uma das faces. Todas são iguais. O objetivo é provocar no visitante a sensação de que todos somos vítimas das violações dos direitos humanos: "[...] todos, los desaparecidos y los que quedan. Se refiere a la pérdida para la vida del país, y se abre a la experiencia humana universal de la muerte, la desaparición, el recuerdo y la presencia" (MUSEO DE LA MEMORIA, 2016). Assim, a obra não tem como objetivo realizar um resgate fetichista da memória dos traumas vividos no Chile, mas sim, conscientizar e sensibilizar para o presente e para o futuro; para a ação política.

Como nos ensina Baitello (2005), o espaço das imagens e das representações é um importante terreno de embates políticos. As imagens servem tanto para a dominação quanto para a criação.

Não obstante, não é necessário que as imagens sejam representações "realistas" do passado e dos traumas causados pelo terrorismo de Estado. Muito pelo contrário. É justamente no jogo com as imagens, na relação com os sentidos, na interação e, sobretudo, no poder da imaginação que a obra Geometria de la conciencia contribui para a sensibilização e para a conscientização política.

O signo da memória é constituído pela tensão "entre dois sentidos que lhe são constitutivos: a recordação e a imaginação" (SOARES; QUINALHA, 2011, p. 79). Meio de acesso ao passado recente, a memória é capaz tanto de trazê-lo ao presente quanto de recriá-lo, incorporando a ele novos elementos.

Embora por muito tempo tenha sido concebido que imaginação e recordação fossem operações excludentes - enquanto a imaginação estava voltada para o terreno do irreal e do fantástico, a recordação estava voltada diretamente para a recuperação fiel do passado (SOARES; QUINALHA, 2011, p. 59) - hoje é amplamente aceita a concepção de que a dimensão imaginativa é uma forma de conhecimento tão legítima quanto a rememoração. Mais: ambas compõem uma unidade dialética.

Na obra Huellas, da artista americana Kaarina Kaikkonen (fig. 2), a relação entre imaginação e memória é reforçada através da dialética entre o concreto e o simbólico. 


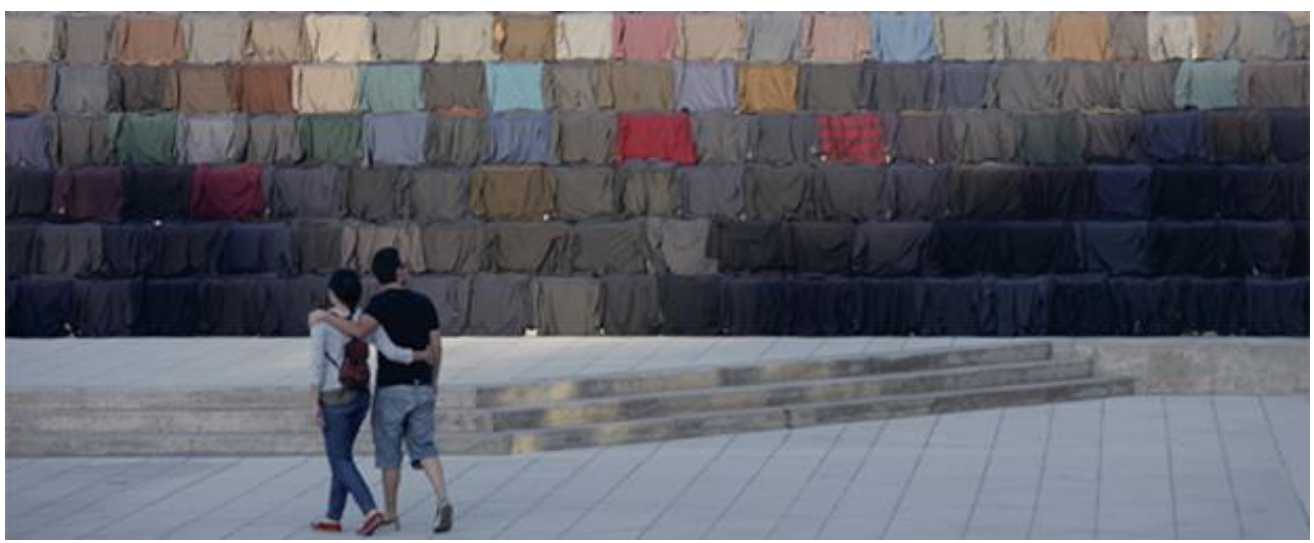

Fonte: Arquivo pessoal

A obra foi exposta de 19 de março a 30 de julho de 2013, no Museo de la Memoria e no Museo Nacional de Bellas Artes do Chile. No museu de Bellas Artes, camisetas e blusas ficaram presas numa espécie de varal que atravessava grande parte de uma das áreas abertas do interior do prédio, já no Museo de La Memoria as camisetas e blusas foram colocadas nas escadas das ruas localizadas nas imediações da instituição. Essas "ropas, coleccionadas o compradas, fueron usadas por personas anónimas cuya identidad es desconocida, sus historias no narradas y su ausencia nos provoca recuerdos" (MUSEO DE LA MEMORIA). Assim, os espectadores foram convidados a "imaginar dónde estará esta gente y adivinar sus historias a medida que vamos recreando su presencia" (MUSEO DE LA MEMORIA).

Nesse processo, o tempo é revestido de profundidade e a relação com espaço urbano torna-se um diálogo produtivo. As camisetas nas escadas rompem a visada automática e rotineira ao estabelecer uma ruptura no cotidiano. O ordinário (as escadas), torna-se um elemento de maravilhamento (de sua raiz etimológica: mirablia, mirada). O invisível torna-se visível: o "olhar fadigado", que pouco distingue por conta do excesso de imagens entra em contato com o passado de violência a partir da visão excêntrica ao cotidiano, das camisetas. E nesse percurso, o tempo do passante modifica-se: este é retirado da rotina mecânica e efêmera, 
inerente à lógica da sociedade contemporânea, ao ser convidado a pensar sobre as articulações entre o passado, o presente e o futuro.

Já no caso do Proyeto ADN, de Máximo Corvalán-Pincheira (Fig. 3 e Fig. 4), exposto de 4 de julho a 19 de agosto de 2014, o corpo está presente e opera como dispositivo imagético de rememoração. Feito com restos de corpos iluminados com dispositivos elétricos e tecnológicos a obra é uma mescla entre o sinistro e o belo, entre o orgânico e a máquina. 
Figura 3 - Reprodução parcial do Proyeto ADN

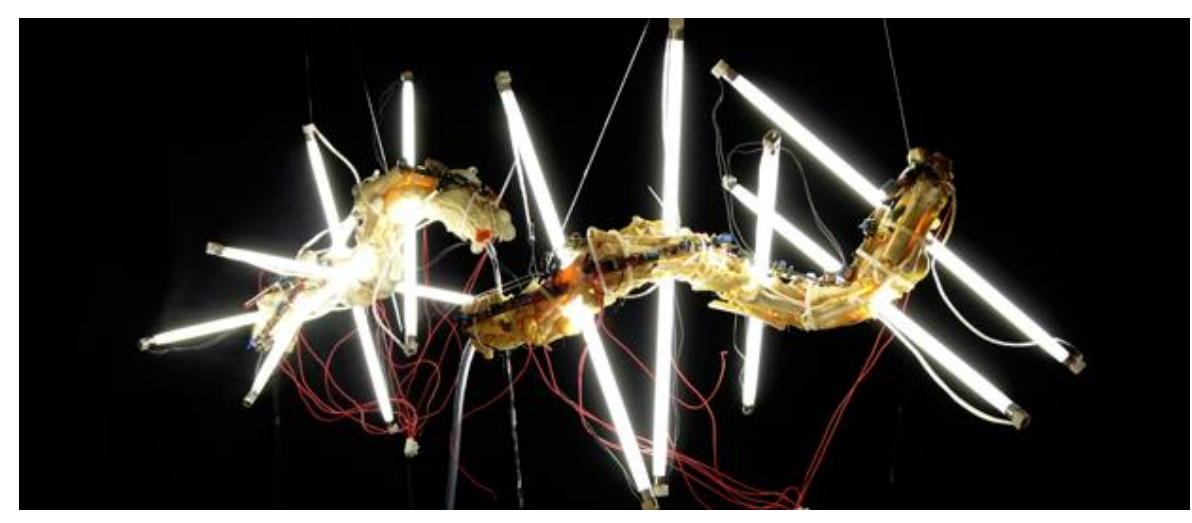

Fonte: Museo de la Memoria e los Derechos Humanos. Disponível em:<- https://ww3.museodelamemoria.cl/>. Acesso em: 10 abr. 2017.

Figura 4 - Vista ampla do Proyeto ADN

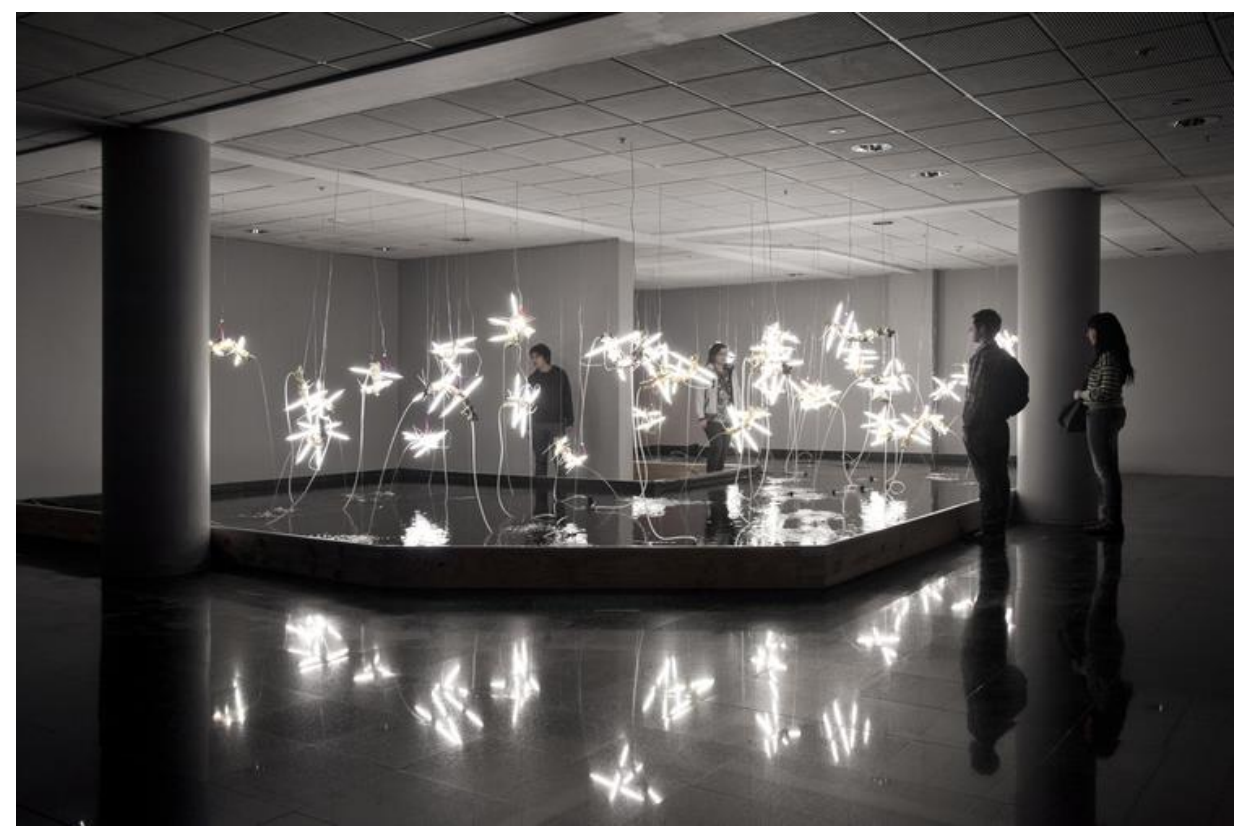

Fonte: Museo de la Memoria e los Derechos Humanos. Disponível em:<https://ww3.museodelamemoria.cl/>. Acesso m: 10 abr. 2017.

Nessa obra, os campos da arte, da ciência e do conhecimento se confundem num ícone que exprime uma das características da era contemporânea, conforme definida por Baudrillard (1991, p. 13): "a contaminação respectiva de todas as categorias, a substituição de uma esfera por outra, a confusão de gêneros [...]". Em contrapartida, aqui a "promiscuidade" entre os 
campos não indica o fim da arte, tampouco da política, como proclamava Baudrillard. Os corpos modificados, remetem ao preocesso atual de identificação dos mortos desaparecidos durante a ditadura civil-militar a partir da tecnologia do exame de DNA.

Desta forma, o lado positivo da tecnologia é destacado: ela permite que os parentes das vítimas possam finalmente descobrir seus paradeiros. Aqui a tecnologia não remete à experiência de descontinuidade temporal. Na obra, o presente e o passado são conectados, e via o assombro busca-se a produção de conhecimento sobre as dimensões de controle e de repressão da ditadura no Chile.

\section{Apontamentos finais}

A despeito das mudanças na concepção e experiência do espaço-tempo na era da cibercultura, não podemos chegar à conclusão que não existe mais tempo, espaço e lugar. O que ocorre é uma mudança em nossa percepção, sensação e modos de experimentar essas categorias A paradoxal relação entre instantaneidade do tempo e recuperação/mercantilização do passado, conforme Huyssen (2014), é um dos sintomas da complexidade das relações sociais no contexto contemporâneo.

Tampouco podemos aceitar que o excesso de informação e de imagem signifique o fim da comunicação e/ou o fim da política. O diagnóstico acerca da sociedade contemporânea feito por Virilio (2008) e de Baudrillard (1991) a despeito de ser em grande parte acurado, pode encerrar uma postura política pessimista que leva a renunciar a todo e qualquer projeto de transformação da sociedade.

A leitura dos dois autores é crítica na medida em que expressa o que Kaplan (1993) denomina mal-estar na pós-modernidade, quer dizer, na medida em que identifica uma profunda crise da sociedade contemporânea. No entanto, a crítica não pode se encerrar nela mesma. Dela devemos tirar as consequências e encontrar brechas para a ação política — conforme é feito por Lyotard (2004) e, os já mencionados nesse artigo, Harvey (2001), Baitello (2005) e Machado (2001).

Os desafios para a ação política em nossa sociedade são enormes. No caso de nosso objeto, talvez ainda maiores. Qual o lugar da memória coletiva na construção de projetos 
políticos emancipatórios? Que memórias que evocamos? Faz sentido pensar projetos museológicos num contexto de pulverização temporal?

Essas questões são atravessadas por diversos debates existentes nos campos acadêmicos, políticos e museológicos acerca das formas legítimas de rememoração de eventos traumáticos e sistemáticas violações dos direitos humanos. Em linhas gerais, o debate sobre as possibilidades de representação do passado traumático pode ser resumido na polêmica entre o filósofo e historiador francês Georges Didi-Huberman e o pesquisador Claude Lanzmann, diretor do documentário Shoah (filme de nove horas sobre o Holocausto em que são usados apenas testemunhos de sobreviventes). Para este último não é possível haver representações em imagens da violência sistemática dos nazistas. Só é legítimo o relato do testemunho oral - de quem "esteve lá" e experenciou no corpo e na alma a violência. Já para Didi-Huberman (2004), as imagens, sobretudo os registros fotográficos, permitem trazer os vestígios que sobreviveram ao projeto nazista de não deixar rastros dos extermínios em massa e, nesse processo, dirigemse ao inimaginável (o horror que transborda as fronteiras da razão) revelando parte da realidade histórica.

A complexidade desse debate é tão maior na medida em que ele envolve, por um lado, a rememoração de acontecimentos de grave violência, na qual a própria condição humana é colocada em dúvida, por outro uma situação paradoxal: os acontecimentos traumáticos são difíceis de lembrar - tanto no plano emocional de seus envolvidos quanto no plano de seus formatos de representação — , mas ao mesmo tempo são difíceis de esquecer, "impossibilitando a mera recusa, pela negação, de um passado indesejado" (SOARES; QUINALHA, 2011, p. 79).

Mais: não devemos esquecer que os museus como o Museo de la Memoria y los Derechos Humanos constituem somente uma parte das instituições interessadas em promover a justiça e a igualdade. A construção e a comunicação das memórias coletivas envolvem um esforço conjunto e articulado entre essas instituições. Nesse caminho, o diálogo entre essas instituições e o campo escolar, no papel de agente multiplicador, é fundamental. Só assim ganharemos as batalhas de sentido travadas na arena da sociedade civil. 


\section{Referências}

BACCEGA, Maria Aparecida. Comunicação/Educação: relações com o consumo.

Comunicação, Mídia e Consumo, São Paulo, v. 7, n. 19, p. 49-65, jul. 2010.

BACCEGA, Maria Aparecida. "O consumo no campo comunicação/educação: importância para a cidadania”. In: ROCHA, Rose de Melo; CASAQUI, Vander (Orgs.). Estéticas midiáticas e narrativas do consumo. Porto Alegre: Sulina, 2012. p. 248-267.

BAITELLO, Norval. A era da iconofagia: ensaios de comunicação e cultura. São Paulo: Hacker, 2005.

BAUDRILLARD, Jean. La transparencia del mal. Barcelona: Anagrama, 1991

CANEVACCI, Massimo. Fetichismos visuais: corpos eróticos e metrópole comunicacional. São Paulo: Ateliê, 2008.

CHAUI, Marilena. Cultura e democracia. Crítica y emancipación. Revista latinoamericana de Ciencias Sociales, Buenos Aires, v. 1, n. 1, p. 54-76, jun. 2008.

DIDI-HUBERMAN, George. Imagenes pese a todo: memoria visual del holocausto. Barcelona: Paidós Ibérica, 2004.

HARVEY, David. Condição pós-moderna. São Paulo: Loyola, 2001.

HUYSSEN, Andreas. Andreas Huyssen: mídia e discursos da memória. Entrevista concedida a Sonia Virginia Moreira e Carlos Alexandre de Carvalho Moreno. In: MELO, José Marques; MORAIS, Ovando de. Vozes da democratização e cidadania: a polêmica global-local. São Paulo: Intercom, 2011. p. 327-335. (Coleção Memórias, v. 4).

HUYSSEN, Andreas. Políticas de memória no nosso tempo. Lisboa: Universidade Católica Editora, 2014.

KAPLAN, Ann. O mal-estar no pós-modernismo. São Paulo: Zahar, 1993

LINDSTROM, Martin. Brandsense: a marca multissensorial. São Paulo: Bookman, 2005.

LYOTARD, Jean F. A condição pós-moderna. São Paulo: José Olympio, 2004.

MACHADO, Arlindo. Máquina e imaginário. São Paulo: Edusp, 2001.

MENESES, Ulpiano T. Bezerra de. Do teatro da memória ao laboratório da História: a exposição museológica e o conhecimento histórico. Anais do Museu Paulista: História e Cultura Material, São Paulo, v. 2, n. 1, p. 9-42, dez./jan. 1994.

MUSEO DE LA MEMORIA Y DE LOS DERECHOS HUMANOS. Disponível em: <http://www.museodelamemoria.cl/>. Acesso em: 22 dez. 2016. 
SARLO, Beatriz. Tempo passado: cultura da memória e guinada subjetiva. São Paulo: Cia. das Letras, 2005.

SELIGMANN-SILVA. Márcio. Memoria, história e cultura do testemunho. In: SEMINÁRIO: Memória, memoriais e o futuro das democracias. São Paulo: Instituto de Estudos Avançados da USP, 2014.

SOARES, Inês Virgínia Prado; QUINALHA, Renan Honório. Lugares de memória no cenário brasileiro da justiça de transição. Revista Internacional de Direito e Cidadania, São Paulo, n. 10, p. 75-86, jun. 2011.

VIRILIO, Paul. O paradoxo da memória do presente na era cibernética. In: CASALEGNO, Frederico (Org.). Memória cotidiana: comunidades e comunicações na era das redes. Porto Alegre: Sulina, 2006.

VIRILIO, Paul. O espaço crítico. São Paulo: Editora 34, 2008.

Felipe Correa de Mello - Escola Superior de Propaganda e Marketing - ESPM. São Paulo | São Paulo | Brasil. Contato: felipeccmello79@hotmail.com 